$\underline{\text { Research article }}$

\title{
Selecting patients who can be re-challenged with Nevirapine in case of skin rash with Efavirenz - A Study
}

\author{
N Dutta ${ }^{1}$, D Modak $^{2}, \mathrm{R} \mathrm{De}^{1}, \mathrm{~S} \mathrm{Pain}^{3}, \mathrm{SK} \mathrm{Guha}^{2}$ \\ Sri Lankan Journal of Infectious Diseases 2017 Vol.7 (1):18-27 \\ DOI: http://doi.org/10.4038/sljid.v7i1.8120
}

\begin{abstract}
Introduction and Objectives: A common adverse effect of Efavirenz (EFV) - a first line drug used in treatment of patients with HIV infections is skin rash. In case of EFV-induced skin rash, the usual practice is to switch to a Protease Inhibitor (PI), as another nonnucleoside reverse transcriptase inhibitor (NNRTI) might have cross-reactivity with a higher incidence of skin rash which is often severe. The aim of the study was therefore to determine whether with careful evaluation and stratification, using predefined criteria of patients who developed rash with EFV, it might be possible to find a subset of patients among whom Nevirapine (NVP) may be safely used, sparing PIs for second-line treatment.
\end{abstract}

Methods: Of 7000 ART naive patients initiated on EFV in an 18 month period from November 2014 to April 2016, 97(1.9\%) developed a rash. Patients developing rash with EFV were carefully selected using predefined criteria: grade of rash (only Grade I/II rash were selected), hepatic function, age, gender and CD4 levels (males $>400$ cells $/ \mathrm{cmm}$ and females $>250$ cells $/ \mathrm{cmm}$ were excluded if hepatic function was deranged), co-infection status (Hepatitis B/C were excluded), opportunistic infections, concomitant use of other drugs. Based on these stratification criteria, 23 of the 97 patients were selected for challenge with NVP.

Results: Of the 23 selected patients, only 3 (13\%) patients developed recurrence of rash, all being mild in nature.

Conclusions: In carefully selected patients, challenge with NVP can be done in case of rash with EFV as the theory of cross-reactivity does not always hold true. This might help spare PIs in the initial phase, which could then be used as second line therapy - a particularly helpful strategy in developing countries, where newer drugs are still not available under public health programmes.

Keywords: Intolerance to EFV, Re-challenge, Same class NNRTI, Class reactivity, Strategic selection

\footnotetext{
${ }^{1}$ Centre of Excellence in HIV Care, School of Tropical Medicine, Kolkata

${ }^{2}$ School of Tropical Medicine, Kolkata

${ }^{3}$ I.P.G.M.E.R Hospital, Kolkata

Address for correspondence: Dr Nivedita Dutta ; T-6,F-7/6, Ruchira Residency, 369 Purbachal Kalitala Main Road, Kolkata 700078 Telephone:9831124545 ; Email: drniveditad@ gmail.com
} 


\section{Introduction}

Considerable progress has been made in the treatment of HIV infection over the past few decades with the introduction of antiretroviral medications. The HIV/AIDS related morbidity and mortality scenario has shifted from one that was life threatening to a more chronic infection. As more and more subjects are being treated for HIV on a long term basis, the pressing need today is to sustain them on effective and, particularly, for a developing country like India, affordable antiretroviral regimens. Regimens should be potent and the benefits must outweigh the risks associated with its therapeutic use.

Initiating an anti-retroviral regimen with two NRTIs (nucleos[t]ide reverse transcriptase inhibitors) together with a NNRTI (non-nucleoside reverse transcriptase inhibitors) is the latest recommendation by WHO for naïve patients in low and middle income countries. ${ }^{1}$ NNRTI's have become one of the key components of first line antiretroviral treatment (ART) as they are affordable, efficacious and capable of reducing the viral load quickly. However, they are prone to single mutations in the virus causing cross class resistance. ${ }^{2,3,4}$ Though long term toxicities of NNRTIs are less, their propensity to have interactions with other drugs often limits their use.

Among the four major NNRTI, only nevirapine (NVP) and efavirenz (EFV) are commonly used, with rilpivirine and etravirine being less frequently prescribed. Virologic failures have been reported with rilpivirine in subjects who had pre-treatment low CD4 and a high viral load, whereas etravirine use has been limited due to serious hypersensitive skin reactions like Toxic Epidermal Necrolysis (TEN) and Drug Reaction with Eosinophilia and Systemic Symptoms (DRESS syndrome). ${ }^{5,6}$ In comparison, NVP, a dipyridodiazepinone and EFV, a benzoxazinone, have shown better tolerability and antiretroviral efficacy. ${ }^{7,8}$

Skin rash is the key adverse effect observed with NVP and EFV. ${ }^{9,10}$ Their individual propensities to cause side effects differ, with NVP showing a higher risk of cutaneous and hepatic reactions, and EFV, in addition to skin rash, having a higher risk of central nervous system effects. ${ }^{9,11-14}$ Skin rash with NVP has been documented with an overall incidence of $17-32 \%$, while EFV has a lesser risk $(10-27 \%)$ on initiating the drug. ${ }^{14-17}$ The incidence of severe rashes with EFV is only $0.1 \%$, compared to $0.3 \%-1 \%$, as reported with NVP. ${ }^{11,12,17-19}$

There are several studies and case reports on the safety of switching of NNRTI in the event of a skin rash. Mehta and Maartens, in a meta-analysis in 2007, observed that recurrent reactions occurred in $12.6 \%$ of patients with rash who were switched from NVP to EFV, compared with $50 \%$ of those switched from EFV to NVP. Though the cross reactivity seems higher in the latter group, the number of substitutions from EFV to NVP was seen in only 16 subjects compared with NVP to EFV substitutions in over 239 reported cases. ${ }^{19}$ Similarly, in a study conducted on Thai patients in 2006, by Manosuthi et al, only 10 (8.2\%) of 122 patients who had NVP rash developed rash from EFV, leading to its discontinuation. ${ }^{20}$

Clinical safety data regarding use of NVP in HIV-infected patients with preceding EFV associated rash are still quite limited, ${ }^{13,21}$ whereas, switching from NVP to EFV in cases of skin rash or hepatotoxicity have seemed safer and effective. Accordingly, most clinicians are unwilling to challenge patients with NVP once rashes have been documented with EFV as both are from the same class of NNRTI and higher incidence of severe rashes associated with 
NVP makes such switch unsafe. Hence, once hypersensitivity to EFV is reported, patients are shifted to protease inhibitor (PI) based regimens, limiting their future treatment options.

HIV care in India is under the umbrella of the National AIDS Control Organisation (NACO).There are 10 Centre of Excellences (COE) which overview the functioning of around 512 antiretroviral centres (ART) across the country and act as referral centre for all patients with HIV/AIDS. Weighing affordability and efficacy together, the initially prescribed first line antiretroviral regimen comprises of two nucleos(t)ide reverse transcriptase inhibitors (NRTI) and one non nucleoside reverse transcriptase inhibitor (NNRTI). From November 2014, a single pill regimen containing both these classes is available (Tenofovir, Lamivudine and Efavirenz). Since EFV is prescribed on a large scale basis, there have been several documented events of rash in patients after starting this regimen. The majority of these rashes have been attributed to EFV and in all such cases of hypersensitivity, EFV is substituted with a Protease Inhibitor (PI) based regimen. As treatment options with third line regimens like Raltegravir, Maraviroc or Dolutegravir is very limited in India, careful evaluation of all confounding factors as well as demographic factors along with grading of the rash should be given due consideration before substituting NNRTI with PI.

A study was therefore conducted to assess the feasibility of using another NNRTI e.g. NVP in case of EFV rash at a tertiary care referral centre.

\section{Methods}

According to the updated Indian National guidelines on Highly Active Antiretroviral Treatment (HAART) published in November, 2014, ART is initiated with 2 NRTI (Tenofovir and Lamivudine) along with 1 NNRTI (Efavirenz) for ART naive patients. The usual regimen is a once daily pill of Tenofovir, Lamivudine and Efavirenz. Patients who have been initiated on first line ART prior to November, 2014 with Zidovudine, Lamivudine and Nevirapine were retained on the same regimen. A small cohort of patients who were already on Tenofovir, Lamivudine and Nevirapine (TDF/3TC/NVP) were shifted to Tenofovir, Lamivudine, Efavirenz (TDF/3TC/EFV) as NVP was gradually withdrawn and replaced with EFV in the first line ART regimen. Some of these patients subsequently developed EFV rash, despite having tolerated NVP as their first line ART regimen. Hence, there were 2 groups of people who were re-challenged from EFV to NVP, one with prior ART (NNRTI) exposure (with NVP) and another ART naive.

At the Centre of Excellence in HIV Care (COE) attached to the School of Tropical Medicine, Kolkata, India, all patients with EFV rash from November 2014 till April 2016 (18 months) were evaluated. During this time approximately seven thousand ART naive patients were initiated on EFV based first line ART keeping this COE as the referral centre. Of the 7000 patients, 97 (1.9\%) had rash with EFV.

Patients were included in the study after thorough assessment of all the risk factors including severity \& grading of rash (Table 1), age, gender, ethnicity, current CD4+Tcell count, presence of opportunistic infections, history of concomitant drug intake and baseline liver function (Table 2). Each of these factors was taken into consideration before substituting NVP for EFV in subjects presenting with EFV hypersensitivity. 
Table 1 Grading of rash

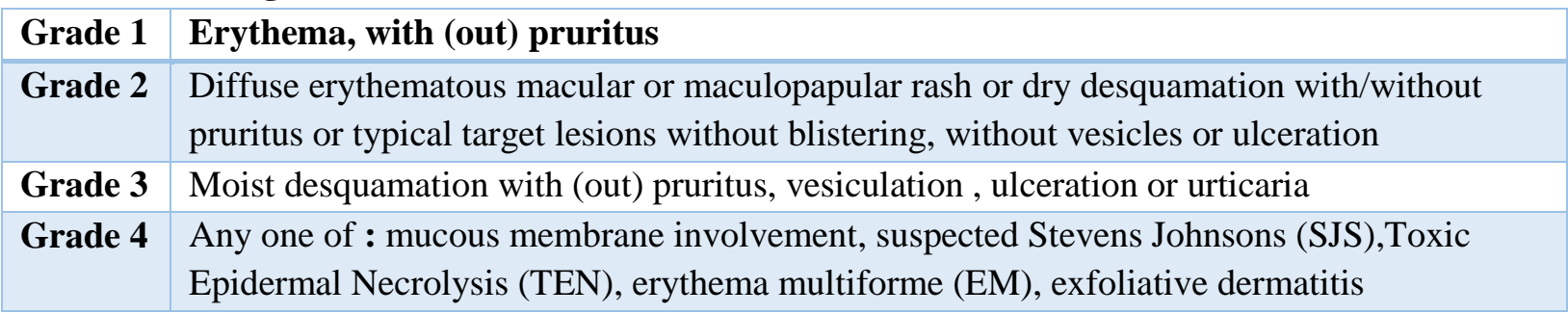

(Source: Division of AIDS, National Institute of Allergy and Infectious Diseases; USA) ${ }^{22}$

The strategy of whether to switch to NVP or to PI based regimen in a case of EFV rash was adopted after thorough clinical and laboratory evaluation.

Institutional Ethics Committee approval was obtained before such switchover was done.

Table 2: Criteria for exclusion from NVP challenge in patients with EFV rash $(n=97)$

\begin{tabular}{|c|c|c|}
\hline Risk factor & Criteria for exclusion & Numbers Excluded \\
\hline Grading of rash & Grade 3 or 4 rash & $\begin{array}{l}46(47.4 \%) \\
-\quad \text { Grade } 3 \text { rash - } 38 \\
\text { - } \quad \text { rash involving } \\
\text { mucosa - SJS type }-8 \\
\text { None progressed to TEN }\end{array}$ \\
\hline Age & $<15$ years & 3 \\
\hline $\begin{array}{l}\text { CD4 count, } \\
\text { gender and } \\
\text { concomitant } \\
\text { liver } \\
\text { dysfunction }\end{array}$ & 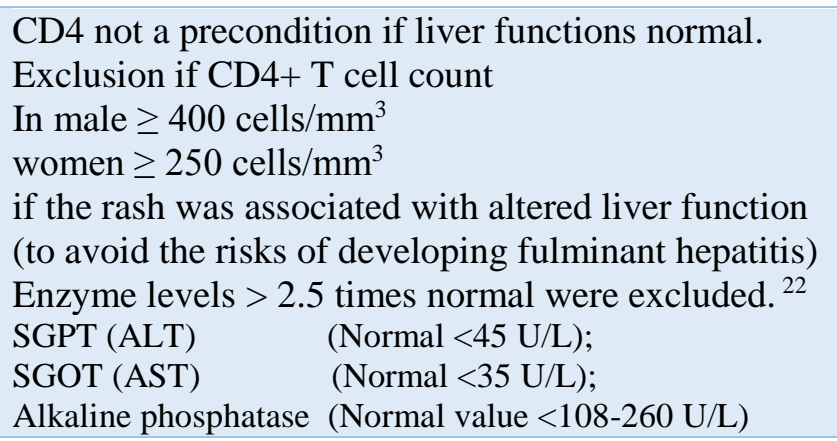 & $\begin{array}{l}\text { Women- } 26(26.8 \%) \\
\text { Men } \quad-15(15.4 \%)\end{array}$ \\
\hline Co-infections & Hepatitis B or C & $5(5.15 \%$ \\
\hline $\begin{array}{l}\text { Concomitant } \\
\text { use of other } \\
\text { drugs }\end{array}$ & $\begin{array}{l}\text { Suspected rashes due to co-administration of } \\
\text { cotrimoxazole and antitubercular drug }\end{array}$ & $2(2.06 \%)$ \\
\hline $\begin{array}{l}\text { Opportunistic } \\
\text { infections }\end{array}$ & $\begin{array}{l}\text { Not considered as an exclusion criteria } \\
\text { (A few patients were also on antitubercular drugs (ATD) } \\
\text { and possibility of rashes with any of this were excluded by } \\
\text { withholding ATD for few days and evaluating progression } \\
\text { of rash before the re-challenge) }\end{array}$ & \\
\hline
\end{tabular}

A total of 74 patients were excluded from the re-challenge using the criteria shown in Table 2 and 23 patients were included into the study. There were 7 patients who had past exposure to NVP, had tolerated it but were then shifted to EFV and developed a rash. The remaining 16 were ART naive patients who had rash with EFV. Hence, there were 2 groups of people who were rechallenged from EFV to NVP, one with prior ART (NNRTI) exposure (with NVP) and 
another ART naive. All re-challenged patients were followed up for 24 weeks from the date of switch.

\section{Results}

Twenty three patients $(n=23)$ who developed EFV related skin rash were entered in the study. Their baseline parameters are shown in Table 3. Of these 23, 16 were ART naïve patients (no history of previous exposure to NVP). There were 3 amongst these 16 (13.04\%) who failed to tolerate NVP challenge. However none of the 7 patients who developed EFV related skin rash and had a prior history of NVP exposure developed a rash with NVP re-challenge.

Table 3: Baseline parameters of study population in whom switch was made from EFV to NVP $\mathrm{n}=23$

\begin{tabular}{|c|c|}
\hline Characteristics & Observation in 23 patients \\
\hline \multicolumn{2}{|l|}{ Age in years } \\
\hline Mean ; Median ; Range & $32.6 ; 38 ; 15-56$ \\
\hline Sex ratio (m:f) & Male $12(52.17 \%)$ : Female $11(47.83 \%)$ \\
\hline Ethnicity & $\begin{array}{l}\text { All Indian origin Asians } \\
\text { No patients of Hispanic, Chinese or } \\
\text { African origin }\end{array}$ \\
\hline \multicolumn{2}{|l|}{ CD4+ T cell count, cells $/ \mathbf{m m}^{3}$} \\
\hline Mean ; Median ; Range & $314 ; 335 ; 47-724$ \\
\hline Range in men / women & $47-562 / 222-515$ \\
\hline \multicolumn{2}{|l|}{ Grade of rash } \\
\hline Grade 1 & 8 \\
\hline Grade 2 & 15 ( only 2 had mild fever) \\
\hline \multicolumn{2}{|l|}{ History of ART exposure } \\
\hline $\begin{array}{l}\text { Patients with past exposure to NVP, tolerated it but } \\
\text { were then shifted to EFV and developed a rash }\end{array}$ & 7 \\
\hline ART naive patients who had rash with EFV & 16 \\
\hline \multicolumn{2}{|l|}{ Time from initiation of EFV to appearance of rash } \\
\hline Mean duration & 15.4 days \\
\hline Range & 2-51 days \\
\hline
\end{tabular}

Table 4: Most common rash presentations*

\begin{tabular}{|l|l|}
\hline Erythema & $\mathbf{2}$ \\
\hline Morbilliform rash (macular) & 4 \\
\hline Papular rash & 1 \\
\hline Maculo-papular rash & 9 \\
\hline Mild pruritus & 3 (only pruritus) \\
6 (Pruritus with maculopapular rash) \\
\hline $\begin{array}{l}\text { Rash mild grade (but not well } \\
\text { specified) }\end{array}$ & 2 \\
\hline Rash with mild fever & 2 \\
\hline *features are documented with some overlapping
\end{tabular}

Of the 23 patients re-challenged with NVP, $20(86.96 \%)$ remained on NVP and were followed up for 24 weeks for any adverse effects. Of these 20,7 patients $(35 \%)$ had a prior history of exposure to NVP and tolerated it again following a short period of 
EFV hypersensitivity. The CD4 T cell count at the time of substitution in the 3 patients in whom NVP was discontinued was 207 (male), 321(male) and 263 (female) cells/cumm. Though, the recurrence of rash with NVP challenge was mild and of grade 1 in most patients (Table 4), the drug was discontinued, as pre-defined on our study criteria.

\section{Discussion}

Drug-induced skin rash has been one of the major reasons behind discontinuation of EFV.

EFV is an integral part of the standard first-line anti-retroviral therapy regimen in India and a considerable number of patients who develop skin rash are shifted from an EFV-based regimen to a PI-based regimen, because most clinicians are unwilling to risk challenge with NVP once rashes have been documented with EFV, as both are from the same class of NNRTI and have a possibility of sharing drug related hypersensitivity.

The chemical structure of a drug is the primary factor for determining its conversion to a toxic metabolite. However, other risk factors and patient characteristics such as genetic polymorphism also play an important role in the event of drug toxicity. ${ }^{23} \mathrm{HIV}$ infection itself has been shown to affect the drug metabolic pathway as it is associated with a glutathione (GSH) depleted state. Glutathione plays an important role in the conjugation and metabolism of drugs and hence, in HIV infection, this typical detoxification pathway is hampered. ${ }^{24,25}$ Genetic polymorphisms have a major effect on how a drug is being metabolised, influencing its bio activation and detoxification. In some studies skin rash has been shown to be related to a CYP2B6516TT polymorphism. ${ }^{26,27}$

Rash with NVP has been documented with an overall incidence of $17-32 \%$, although $13 \%$ of these are mild rashes. Generally, NVP rashes are transient with risk being greatest in the first 6 weeks of treatment. ${ }^{15,16,28}$ However, more severe incidents including extensive maculopapular rash, serum sickness-like reaction, hypersensitivity syndromes, SJS and TEN have also been reported. ${ }^{29,30,31,32}$ Some studies have shown that the recommended lead-in dose of NVP $200 \mathrm{mg}$ once daily for 14 days prior to escalation to $200 \mathrm{mg}$ twice daily has reduced the frequency of rash. ${ }^{33}$ In our study, as most participants had discontinued an EFV based regimen for more than 2 weeks at the time of presentation with a history of a rash, NVP was started with a lead-in dose of $200 \mathrm{mg}$ once daily for 2 weeks followed by advice to continue $200 \mathrm{mg}$ twice daily.

EFV has risk of rash in 10-27\% of patients starting the drug, but is rarely associated with true hypersensitivity reactions with fever or internal organ involvement. Most EFV-induced rashes are mild to moderate with severe rashes (SJS, TEN, EM) reported in only $0.1 \%$ of patients, compared with $0 \cdot 3-1 \%$ as reported with NVP. ${ }^{11,12,17-19}$

Although female sex and ethnicity are related to the risk of rash with NVP, there is limited data on risk with EFV. ${ }^{34}$ Studies by Kiertiburanakul and Sungkanuparph (2009) ${ }^{35}$ from Thailand have attributed association of both AIDS-defining illness and high CD4 cell counts at the time of NVP initiation to be associated with NVP-associated rash (Median CD4 cell count at the time of NVP initiation was higher among patients in rash group). The prominence of rash in females is possibly related to autoimmune diseases in women who have stronger humoral and cellular responses than men, hence the commonly observed CD4 
and sex dependent toxicity profile related to NVP treatment. NVP shows immunecompetence linked toxicity such that patients with a higher CD4 count and a detectable viral load are seen to be more susceptible to risk of symptomatic hepatic adverse events. ${ }^{27,36,37}$

Switching from NVP to EFV in cases of hepatotoxicity has seemed safe and effective. As observed by Walubo et al (2006) ${ }^{38}$, NVP induced hepatotoxicity and liver injury has close association with enzyme induction. Hepatotoxicity occurs more frequently with NVP (1.4$17 \%)$ than with EFV (1.1-8\%). ${ }^{39}$ Hepatotoxicity in the initial days of ART associated with rash, fever and other constitutional symptoms are seen with NVP but is very rare with EFV use. The DRESS Syndrome though well documented with NVP has been only once documented as a case on record with EFV. ${ }^{34,31}$ Therefore substituting EFV for NVP following hepatotoxicity or cutaneous hypersensitivity appears to be reasonable, provided that the adverse reactions to NVP were not life-threatening.

The previous common understanding about the cross reactivity of NVP and EFV in cases of cutaneous hypersensitivity were based on very little available data. Two previous small case series reported by Clarke et al $(2000)^{21}$ and Soriano et al $(2000)^{13}$ demonstrated that skin rashes related to NVP are not necessarily a class effect. Wit et $\mathrm{al}^{28}$, reporting the results of the ATHENA Cohort Study in 2008 suggested that the majority (>90\%) of HIV infected patients with CD4 counts $>200$ cells/L who had preceding NVP-associated rash could tolerate EFV well, suggesting that use of EFV is safe in these cases. In their study from Thailand in 2006, Manosuthi et $\mathrm{al}^{20}$ also observed that only $8.2 \%$ developed rash associated with EFV following history of rash with NVP and a conclusion was drawn that HIV-infected patients with CD4 counts of $>200$ cells $/ \mathrm{mL}$ who had preceding NVP-associated rash could tolerate EFV well.

On the other hand, NVP re-challenge after discontinuation of EFV have been reported in only a few case series and the number of patients has always been very few. Of the limited data available on switching from EFV to NVP, possibly the largest was the A5095 trial by the AIDS Clinical Trials Group conducted at Washington, where the change from EFV to NVP because of skin symptoms was generally found safe and usually resulted in resolution. Onethird of the total 18 participants who were switched from EFV because of skin symptoms had mild-to-moderate skin hypersensitivity reactions after initiation of NVP therapy, 5 had recurrence while on NVP therapy with only $4(22.2 \%)$ discontinued ${ }^{40}$.

None of the earlier small studies made any attempt to select patients based on pre-defined criteria as a strategy for switch. We think that with predefined criteria for patient selection, the outcome of switch can be safe and may allow participants to remain on NNRTI based regimen sparing the Protease Inhibitor (PI) based regimen for future treatment. In our study, of the 23 EFV rash subjects re-challenged, 20 (86.96\%) remained on NVP and were followed up for 24 weeks for any adverse effects. Those 3 who had rash with NVP were never exposed to NVP in the past. Of the 20 who tolerated NVP, 7 patients $(35 \%)$ had a prior history of exposure to NVP and tolerated it again following a short interim period of EFV hypersensitivity. Hence for these 20 patients the theory of cross reactivity between two NNRTIs did not hold good. 


\section{Conclusion}

The outcome of our study supported further careful evaluation of various confounding factors before concluding that the subject is having cutaneous hypersensitivity to both the NNRTIs in the first line antiretroviral treatment. As we have seen, selected patients developing skin rash with EFV can be tried with another NNRTI e.g. NVP. Further studies are needed to confirm whether careful selection strategy and appropriate assessment of skin rashes can avoid early switch to PI's, thereby sustaining at least a handful of patients on their NNRTI based regimens and improving their chances of long time survival.

\section{References}

1. WHO 2013 consolidated guidelines, First line ART for adults http://www.who.int/hiv/pub/guidelines/arv2013/art/artadults/en/

2. US Department of Health and Human Services (DHHS). Guidelines for the Use of Antiretroviral Agents in HIV-1- Infected Adults and Adolescents. http://AIDSinfo.nih.gov 2004.

3. Pozniak A, Gazzard B, Anderson J, et al. British HIV Association (BHIVA) Guidelines for the treatment of HIV-infected adults with antiretroviral therapy. HIV Med 2003; 4:1-41. doi :10.1046/j.1468-1293.4.s1.3.x

4. Yeni PG, Hammer SM, Hirsch MS, et al. Treatment for adult HIV infection: 2004 Recommendations of the International AIDS Society - USA Panel. JAMA 2004; 292: 251-265. doi :10.1001/jama.292.2.251

5. DHSS guideline for the use of antiretroviral agents in HIV 1 infected adults and adolescents http;//aidsinfo.nih.gov/guidelines accessed on 12/15/2015

6. US food and drug administration, intolerance to etravirine 2009; http ://www.fda.gov/safety/medwatch/safety information/safety alerts for human medical products/ucm180579.htm

7. Ferrer E, Santamarina E, Domingo $P$ et al. Nevirapine-containing regimens in HIVinfected naive patients with CD4 cell counts of 200 cells/microl or less. AIDS 2004; 18:1727-1729. PMID: 15280785

8. Murphy RL, Sommadossi JP, Lamson M, et al. Antiviral effect and pharmacokinetic interaction between nevirapine and indinavir in persons infected with human immunodeficiency virus type 1. J Infect Dis 1999; 179:1116-1123. doi :10.1086/314703

9. Van Leth F, Phanuphak P, Ruxrungtham K et al. Comparison of first-line antiretroviral therapy with regimens including nevirapine, efavirenz, or both drugs, plus stavudine and lamivudine: a randomized open-label trial, the $2 \mathrm{NN}$ Study. Lancet 2004; 363: 1253-1263. doi :10.1016/S0140-6736(04)15997-7

10. WHO. Scaling up antiretroviral therapy in resource-limited settings: treatment guidelines for a public health approach, 2003 revision. Geneva: World Health Organization, 2002. who.int/hiv/pub/prev_care/en/arvrevision2003en.pdf accessed Sept 14,2015

11. Adkins JC, Noble S. Efavirenz. Drugs 1998; 56:1055-64. PMID:9878993

12. Drugs.com. Sustiva product information. http://www.drugs.com/ pro/sustiva.html accessed Sept 28, 2015 
13. Soriano V, Dona C, Barreiro P, González-Lahoz J. Is there cross toxicity between nevirapine and efavirenz in subjects developing rash? AIDS 2000; 14:1672-73. PMID: 10983663

14. Zapor MJ, Cozza KL, Wynn GH, et al. Antiretrovirals, part II: focus on nonprotease inhibitor antiretrovirals (NRTIS, NNRTIs and fusion inhibitors). Psychosomatics 2004; 45:524-35. doi : 10.1176/appi.psy.45.6.524

15. Warren KJ, Boxwell DE, Kim NY, Drolet BA. Nevirapine-associated StevensJohnson syndrome. Lancet 1998; 351:567. doi : 10.1016/S0140-6736(98)24008-6

16. Pollard RB, Robinson P, Dransfield K. Safety profile of nevirapine, a nonnucleoside reverse transcriptase inhibitor for the treatment of human immunodeficiency virus infection. Clin Ther 1998; 20:1071-1092 PMID: 9916603

17. Chaponda M. , Pirmohamed M., Hypersensitivity reactions to HIV therapy, Br J Clin Pharmacol 2011; 7(1):5/659-671/659. doi : 10.1111/j.1365-2125.2010.03784.x

18. DHHS Panel on Antiretroviral Guidelines for Adults and Adolescents. Guidelines for the use of antiretroviral agents in HIV-1-infected adults and adolescents, October, 2006. http://aidsinfo.nih.gov/ContentFiles/AdultandAdolescentGL.pdf accessed Sept 14, 2015.

19. Mehta U., Maartens G. Is it safe to switch between efavirenz and nevirapine in the event of toxicity? Lancet Infect Dis 2007; 7:733-38 doi : 10.1016/S1473-3099(07)70262-1

20. Manosuthi W., Thongyen S., Chumpathat N., et al. Incidence and risk factors of rash associated with efavirenz in HIV-infected patients with preceding nevirapine-associated rash. HIV Medicine 2006; 7:378-382 doi : 10.1111/j.1468-1293.2006.00396.x

21. Clarke S, Harrington P, Barry M, Mulcahy F. The tolerability of efavirenz after nevirapine-related adverse events. Clin Infect Dis 2000; 31:806-807. doi : $10.1086 / 314026$

22. https://rsc.tech-res.com/clinical-research-sites/safety-reporting/daids-grading-tables. Site accessed May 23rd 2016.

23. Srivastava A., Maggs J.L., Antoine D.J., et al. Role of reactive metabolites in drug induced toxicity, J. Uretrecth (Ed.), Adverse Drug Reactions, Handbook of Experimental Pharmacology,196, Springer, Heidelberg, 2010 pp165-194.

24. Esteban A., Perez-Mateo M., Boix V., et al Abnormalities in the metabolism of acetaminophen in patients infected with the human immunodeficiency virus(HIV). Methods Find Exp. Clin. Pharmacol 1997; 19:129-132. PMID: 9151289

25. Townsend D.M., Tew K.D., Tapiero H.; The importance of glutathione in human disease, Biomed Pharmacother 2003; 57:145-155 PMID: 12818476

26. Pereira S.A, Wanke R., Matilde M. et al. Insights into the role of bioactivation mechanisms in the toxic events elicited by Non Nucleoside Reverse Transcriptase inhibitors; Advances in Molecular Toxicology ; Elsevier 2012 Volume 6; 1:3-4.

27. Yuan J., Guo S., Hall D., et al. The nevirapine toxicogenomics study team: Toxicogenomics of nevirapine-associated cutaneous and hepatic adverse events among populations of African, Asian and European descent, AIDS 2011; 25:1271-1280 doi : 10.1097/QAD.0b013e32834779df

28. Wit F.W., Kesselring A.M., Gras L., et al. Discontinuation of nevirapine because of hypersensitivity reactions in patients with prior treatment experience, 
compared with treatment-naive patients: the ATHENA cohort study, Clin Infect Dis 2008; 46: 933-940. doi : 10.1086/528861

29. Fagot JP, Mockenhaupt M, Bouwes-Bavinck JN, et al. Nevirapine and the risk of Stevens-Johnson syndrome or toxic epidermal necrolysis. AIDS 2001; 15:1843-1848. PMID: 11579247

30. Metry DW, Lahart CJ, Farmer KL, Hebert AA. Stevens-Johnson syndrome caused by the antiretroviral drug nevirapine. J Am Acad Dermatol 2001; 44:354-357. PMID: 11174414

31. Bourezane Y, Salard D, Hoen B, et al. DRESS (drug rash with eosinophilia and systemic symptoms) syndrome associated with nevirapine therapy. Clin Infect Dis 1998; 27:1321-1322. PMID: 9827291

32. Lanzafame M, Rovere P, De Checchi G, et al. Hypersensitivity syndrome (DRESS) and meningoencephalitis associated with nevirapine therapy. Scand J Infect Dis 2001; 33: 475-476. PMID: 11450872

33. Health Services/Technology Assessment Text (HSTAT).Guidelines for the use of antiretroviral agents in HIV infected adults and adolescents. Washington DC; Department of Health and Human Services (DHHS) and the Henry J. Kaiser family foundation, 2006.

34. Bossi P, Colin D, Bricaire F, Caumes E. Hypersensitivity syndrome associated with efavirenz therapy. Clin Infect Dis 2000; 30:227-28. doi : 10.1086/313629

35. Kiertiburanakul S., Sungkanuparph S., Malathum K. et al, A model and risk score for predicting nevirapine-associated rash among HIV-infected patients: In settings of low CD4 cell counts and resource limitation; Open AIDS J. 2009; 3:24-30. doi : 10.2174/1874613600903010024

36. Tiniakou E, Costenbader KH, Kriegel MA. Sex-specific environmental influences on the development of autoimmune diseases. Clin Immunol 2013; 149:182-91. doi :10.1016/j.clim.2013.02.011

37. Baylor M.S., Johann-Liang R. Hepatotoxicity associated with nevirapine use. $J$. Acquir. Immune Defic. Syndr. 2004; 35:538-539 PMID: 15021321

38. Walubo A., Barr S.,. Abraham A.M. RatCYP3A and CYP2B1/2 were not associated with nevirapine-induced hepatotoxicity, Methods Find Exp.Clin.Pharmacol 2006; 28:423-431 doi : 10.1358/mf.2006.28.7.1003580

39. Martin-Carbonero L, Núñez M, Gonzalez-Lahoz J, Soriano V. Incidence of liver injury after beginning antiretroviral therapy with efavirenz or nevirapine. HIV Clin Trials 2003; 4:115-20. doi : 10.1310/N4VT-3E9U-4BKN-CRPW

40. Jeffrey T. Schouten, Amy Krambrink, Heather J. Ribaudo, et al. Substitution of nevirapine because of efavirenz toxicity in AIDS: Clinical Trials Group A5095; Clin. Infect. Dis. 2010; 50:787-79 doi: 10.1086/650539 